\title{
ARTículo
}

\section{Un acercamiento al extinto pueblo taushiro}

\section{An approach to the extinct Taushiro people}

\section{Danilo Kadesh Hernández Esquerre}

danilo.hernandez@unmsm.edu.pe

Universidad Nacional Mayor de San Marcos

\section{RESUMEN}

Este artículo presenta algunos tópicos del extinto pueblo taushiro, como son su endonimia, cosmovisión y cosmogonía, según la perspectiva de Amadeo García, el último taushiro vivo. Para tal fin, tenemos en cuenta la influencia religiosa que ha experimentado Amadeo dada la vinculación directa que tuvo, cuando joven, con el Instituto Lingüístico de Verano (ILV).

Palabras claves: Taushiro; Amadeo García; Atontu’tua; cosmovisión

\section{ABSTRACT}

This article presents some topics of the extinct Taushiro people, such as their endonymy, worldview and cosmogony, according to the perspective of Amadeo García, the last living Taushiro. For this purpose, we take into account the religious influence that Amadeo has experienced given the direct link he had, as a young man, with the Summer Institute of Linguistics (ILV).

Keywords: Taushiro; Amadeo García; Atontu'tua; worldview. 


\section{Introducción}

Es evidente que un gran número de pueblos nativos han desaparecido por diversas causas. Este fenómeno ha acaecido y acaece en diversas partes del mundo. Sudamérica no es la excepción. En la Amazonía peruana, debido a las correrías por el auge del caucho que experimentaron los nativos a finales del siglo XIX y comienzos del XX, sumado a las diversas enfermedades que padecieron, así como secuestros y masacres de sus niños y mujeres, además de la aculturación de su gente y la desterritorialización debido a la extracción de madera y petróleo, por listar solo algunas causas, los pueblos nativos de esta región se vieron mermados en su demografía, y con ella mermada también la herencia cultural que por milenios guardaron para las posteridades. Muchos de estos pueblos desaparecieron porque, al fusionarse con otros más empoderados, sus gentes optaron por adquirir las costumbres y cultura del pueblo receptor. Otros, la minoría, desaparecieron porque su población fue diezmada. Este último es el caso del pueblo taushiro.

Los taushiro, cuyo territorio en la Amazonía se ubicaba por la quebrada Aucayacu, al suroeste de lo que es actualmente la Reserva Nacional del Pucacuro, en la región peruana de Loreto, es hoy un pueblo inexistente. Cuando existió, hasta la década de los setenta, se mantuvo en condición de aislamiento voluntario, motivo por el cual son exiguos los datos que sobre ellos se posee. Se sabe por Alicea Ortiz (1976a) que en sus últimas décadas conformaron dos subgrupos: los einon'tutua y los atontu'tua.

Los miembros sobrevivientes de los einontu'tua, que mantuvieron algunos vínculos con los mestizos dado su uso preferente del castellano, se casaron con gente foránea, lo que produjo la desaparición de su cultura y lengua en sus posteriores generaciones. Por el contrario, los miembros sobrevivientes de los atontu'tua fueron más reacios a estos contactos. Murieron todos ellos por las diversas epidemias que asolaron su territorio, salvo uno que todavía vive en el pueblo de Intuto (Loreto), Amadeo García ${ }^{1}$.

Amadeo es hoy el último sobreviviente del pueblo taushiro. Gracias a él ha sido posible conocer un poco más la cultura taushiro. Los estudios sobre este pueblo se han concentrado sobre todo en su lenguaje ${ }^{2}$. Hay, no obstante, un número reducido de textos que hablan de los taushiro pero de modo muy sucinto, solo en algún capítulo o parágrafo ${ }^{3}$. El texto de Alicea Ortiz, Apuntes sobre la cultura taushiro (1976a), es prácticamente el único que va más allá del tema lingüístico. Este es un texto breve que, desde la perspectiva de Alicea Ortiz, se limita a la descripción general de las particularidades del pueblo taushiro sin profundizar en algunos tópicos como el sistema de parentesco o la religiosidad, sin decir nada sobre su cosmovisión.

Queremos en este artículo dar un alcance sobre los taushiro desde la perspectiva del último taushiro, Amadeo García, a partir de las distintas entrevistas que mantuvimos con él. Para comprender su actual idiosincrasia nos apoyaremos también en la información que hemos obtenido de los trabajos de algunos investigadores anteriores a nosotros. Nuestro objetivo es brindar algunos alcances sobre esta extinta cultura, tales como su endonimia, cosmovisión y cosmogonía, siendo totalmente conscientes del inevitable sesgo, ya que al menos sobre estas dos últimas cuestiones la única fuente es hoy Amadeo García, pero también reconociendo que no hay posibilidad de otro modo.

\footnotetext{
1 Amadeo García ha afirmado que él es un taushiro atontu'tua, y marca diferencia con los einontu'tua por el hecho de que estos prefirieron hablar castellano mientras que los atontu'tua mantuvieron el uso de la lengua taushiro.

2 Estudios sobre el idioma taushiro incluyen Ortiz (1975a, 1975b, 1975c, 1975d, 1975e, 1976b), Echered (1975), Pérez Ríos (2008) y O’Hagan (2015). Existen otros textos, pero no se han dedicado exclusivamente al lenguaje taushiro sino también al de otros pueblos.

3 Por citar algunos: Villarejo (1943), Ribeiro y Wise (1978) y Chávez (1976).
} 


\section{Sobre Amadeo García, el último taushiro}

Presentemos a Amadeo García, hoy de 69 años, pues por él es que se pueden extraer actualmente los más importantes datos sobre los taushiro, siempre teniendo presente el nivel de subjetividad de sus afirmaciones. Él es el último de los taushiro y el último que habla la lengua de sus antepasados.

El Instituto Lingüístico de Verano (ILV), en los años setenta, logró relacionarse con los últimos taushiro teniendo como principal contacto al más joven de ellos, Amadeo García, de 20 años en aquél entonces ${ }^{4}$. Pero ¿cómo se inició este contacto? La Occidental Petroleum Corporation, empresa petrolera estadounidense, había iniciado acciones de extracción a finales de los años sesenta en la cuenca del río Tigre. Se había voceado la existencia de un grupo nativo oculto por los afluentes del río, por lo que se montó una expedición para encontrarlo. La empresa envío una avioneta vigía para tal fin. Los encontraron, y los taushiro también los vieron desde tierra. Era el año 1971. "Estaban tan cerca del suelo que podía ver sus rostros que nos observaban", recuerda Amadeo5. El contacto, sin embargo, no lo llevó a cabo la empresa, sino fue legado a los misioneros del ILV. Con las coordenadas obtenidas sobre su ubicación, no fue difícil el contacto.

Narra Alicea Ortiz que ese mismo año, Daniel Velie, un integrante del ILV, entabló el primer contacto con los taushiro. Días antes había sobrevolado la zona de los taushiro arrojándoles diversos objetos y comida para facilitar el encuentro. Nos dice Amadeo que no sabían por qué soltaban las bolsas de pan, pero que igual las recogían (comunicación personal, 22 de febrero de 2016). Pasados varios días, recuerda, él estaba pescando en una canoa cuando de pronto escuchó el motor de una lancha que se acercaba: era un gringo de nombre Daniel Velie. Le preguntaron por su padre y Amadeo los llevó hasta su aldea. Como en esos días algunos de sus familiares estaban enfermos, Velie les suministró medicinas en sus posteriores visitas y les indicó cómo cuidarse. Los taushiro, con ademanes, le mostraron su agradecimiento. A manera de compensación, Daniel Velie pidió permiso al padre para que se llevase a Amadeo, el más joven del grupo, hacia Yarinacocha, para que otros investigadores pudieran estudiar con él la lengua taushiro. Ellos aceptaron.

Con toda seguridad, un mundo nuevo se abrió a los ojos de Amadeo García. Fue llevado en hidroavión a Yarinacocha, sede del ILV, y allí fue educado por dos años en los conocimientos básicos de matemáticas y lectoescritura, y en la religión cristiana de corte evangélico. Fue el principal colaborador para el estudio de su lengua y para la traducción al taushiro de algunos pasajes del Génesis y de los evangelios bíblicos. Por este motivo es que hoy Amadeo García sabe valorar la lengua que habla y su cultura extinta, y puede leer y escribir en castellano, aunque con muchas restricciones, y su creencia religiosa es la cristiana evangélica.

En Yarinacocha fue educado junto a otros jóvenes de distintos pueblos indígenas. Amadeo recuerda con agrado algunos de estos pueblos: shipibo, aguaruna, huambisa, urarina, yagua, ticuna, orejones (comunicación personal, 24 de febrero de 2016). Según refiere, fue la primera vez que conoció a jóvenes de otros pueblos y la primera vez, por ende, que escuchó sus lenguas.

4 El Instituto Lingüístico de Verano (ILV), ahora SIL International, es una institución cristiana-evangélica asociada a la Wycliffe Bible Translators, fundada en 1934 por el norteamericano William Cameron Townsend (1896-1982). El ILV también se hizo presente en 23 países del mundo. El ILV se estableció en el Perú en 1946. Su sede se ubicó en Yarinacocha, Pucallpa. Se autoasignó la misión general de llevar la palabra de Dios a todos los pueblos olvidados del mundo, y para tal fin tuvo por objetivo específico traducir la Biblia (sobre todo el Nuevo Testamento) a todas las lenguas existentes.

5 Ver: https:/www.nytimes.com/es/2017/12/29/el-ultimo-hablante-de-una-lengua-ancestral-de-la-amazonia/ 
Amadeo, según su propia confesión, no conoció el cristianismo antes de su contacto con el ILV, ni sus padres tuvieron mayor conocimiento sobre este asunto ${ }^{6}$. Las tradiciones mágicoreligiosas de su pueblo no manifestaban la presencia de un dios, aunque sí de espíritus de la naturaleza (Alicea, 1975, p. 22). El conocimiento de tales verdades allende a su cultura nativa supuso para él una percepción nueva. Afirma Amadeo al respecto:

[Sobre Jesucristo] no conocía nada, hermano, con ellos [con los del ILV] he aprendido la Palabra de Dios, todo [...]. Yo no pensaba que hay un dios, pues hermano. Uno que no conoce ¿cómo va a pensar que hay un dios, pues no? (comunicación personal, 19 de marzo de 2010).

Cuando yo he regresado [de Yarinacocha] a mi tierra, donde mi familia, yo ya le cuento a mi familia, a mi viejo, ya tenemos aquí ["allá" quiso decir] un gringo [que] conoce mejor que nosotros, [que] tenemos un solo dios que da la luz, que da la noche, que ha separado la noche y por eso vivimos en la claridad, y así he contado a mi familia (comunicación personal, 24 de marzo de 2010).

Hoy Amadeo se considera cristiano. Cuando se le preguntó si sigue creyendo en lo que habían creído los taushiro, dijo:

Ya no ya. Ya he cambiado yo eso ya. Ya creemos [creo] solamente [en] un solo dios que tenemos, ya pues. Ya sabemos la historia, pues, joven. La Tali misma me enseñó eso ${ }^{7}$. Yo aprendí con la Tali, ella es la que ha dado [la que me ha contado] todo bonito esa historia (comunicación personal, 19 de febrero de 2016).

Él hoy es enfático: "Estoy conociendo a mi Señor que está en el cielo. A Jesucristo, nada más" (comunicación personal, 19 de marzo de 2010). Por ello, se entiende el por qué de su tristeza cuando hace muchos años perdió su texto bíblico en taushiro, el mismo en el que participó con el ILV para su traducción ${ }^{8}$. José Álvarez, quien conoce a Amadeo desde hace muchos años, ha afirmado que le gustaba leer su "Biblia" (comunicación personal, 11 de abril de 2016), y en relación con esto mismo Amadeo nos ha dicho: "Ya no tengo ya [mi Biblia], pero ya [la] tengo en mi cabeza [...], eso no se olvida" (comunicación personal, 19 de febrero de 2016).

Con lo referido queda claro que Amadeo García abandonó conscientemente las creencias taushiro a partir de la influencia que en este aspecto el ILV tuvo en él. Además de la nueva religiosidad, en el ILV Amadeo García también adquirió otros conocimientos. Aprendió a leer en taushiro (la lectura de su Biblia en taushiro así nos lo demuestra) y en castellano, aunque no de modo fluido, como hemos tenido ocasión de corroborar directamente. Además aprendió a escribir también en castellano, aunque de modo muy rudimentario. Los conocimientos básicos de las matemáticas tampoco fueron ajenos a su formación, sobre todo los de la numeración. Alicea Ortiz menciona al respecto: "Los taushiro no tienen un sistema de números, a excepción de: uno, dos, muchos; basado en los dedos de las manos. Los diez dedos de las manos representan muchos" (Alicea, 1976a, p. 8). En el ILV, Amadeo aprendió a contar, y no solo en castellano sino adjudicó significantes taushiro a esos nuevos números que fue aprendiendo. Así, nos ha dicho que en taushiro se puede contar solo hasta 20 (comunicación personal, 24 de marzo de 2010):

6 Por Pablo Maroni (1988) sabemos que los antiguos taushiro -llamados pinches-, luego del contacto en el siglo XVII fueron establecidos en dos misiones cristianas. Por lo tanto, los antiguos taushiro sí conocieron el cristianismo. No obstante, y debido al aislamiento que posteriormente fueron forzados a elegir, dadas las malas situaciones que experimentaron con los patrones y otras gentes, debieron ir dejando de lado esa religiosidad ajena a su cultura. Esto podría explicar por qué Amadeo García nos dijo que sus padres no conocieron el cristianismo y que, incluso para él, fue una creencia nueva.

7 Neftalí Alicea Ortiz.

8 Este texto bíblico consistía en algunos pasajes del Génesis y de los Evangelios. 
Uno (1): Vachi'canto

Tres (3): Vachine'anto'

Cinco (5): U'contava

Siete (7): Ne'ca'que navanuca

Nueve (9): Ne'ca'que navanuca

Once (11): A'tonuca

Trece (13): A'tonuca ne

Quince (15): Uc contato'

Diecisiete (17): Ne'ca'que ne' tonиса

Diecinueve (19): Achintu jane'
Dos (2): Achini

Cuatro (4): Achintu jané yanantu'

Seis (6): Ne'ca'que navanu'yo

Ocho (8): Ne'ca'que navanuca

Diez (10): Ne'ca'que nava

Doce (12): A'tonuca ni

Catorce (14): Á tonuca uétane

Dieciséis (16): Ne'ca'que neto'

Dieciocho (18): Ne'ca'que ne' tonuca

Veinte (20): Yanujua

Por lo tanto, cuando se le hizo saber que Alicea Ortiz había escrito que los taushiro solo podían contar 1, 2 y mucho, él nos negó tal afirmación sosteniendo que la Tali "no ha agarrado [o comprendido] bien" (comunicación personal, 24 de marzo de 2010). Lo más probable es que los taushiro que Alicea Ortiz conoció solo contaban hasta esas limitaciones, y que luego, tras los estudios de Amadeo García en Yarinacocha, hayan aprendido por y con él a contar más números, y simplemente Amadeo estaría confundiendo los tiempos y por ello es que haya negado que los taushiro solo podían contar 1, 2 y mucho.

Amadeo García manifiesta sobre aquellos años agradables y agradecidos recuerdos, sobre todo por la Tali, pues prácticamente fue ella quien lo vinculó directa y definitivamente con las creencias, costumbres y conocimientos allende a su pueblo. Además, fue Alicea Ortiz quien finalmente se llevó a finales de los años 70 y con el consentimiento de Amadeo, a sus cinco pequeños hijos a Puerto Rico para que se eduquen, ya que Amadeo García era consciente de que él solo no iba a poder mantenerlos dado que su pareja, Margarita Machoa, de origen quichua, lo había abandonado prematuramente.

Es cierto, al llevárselos a Puerto Rico, Alicea Ortiz rompió definitivamente el vínculo entre los hijos de Amadeo y los rezagos de la cultura taushiro. Recuérdese que a finales de los setenta, el padre, la madre y el hermano de Amadeo todavía vivían en la quebrada Aucayacu, y algunos criticaron esta decisión 9 . Pero también es cierto que la cultura y la lengua ya estaban condenadas a su extinción. La misma Alicea Ortiz señaló en su defensa: "Era poco probable que Amadeo les hubiera enseñado taushiro a sus hijos en esas condiciones" ${ }^{10}$. Además, hasta ese entonces no se imaginaba que Amadeo terminaría siendo el hombre que cargaría con el último resquicio de su cultura, pues algunos de sus familiares aún vivían en Aucayacu' ${ }^{11}$.

Hemos considerado importante referir estas particularidades de Amadeo García ya que él se ha convertido en la principal y, hasta podríamos decir, la única fuente sobre los taushiro. Tenemos muy presente, no obstante, el alto nivel de subjetividad de sus afirmaciones, que con seguridad no se exceptúa de sesgos. Por ello, esta presentación sobre los taushiro es básicamente desde la perspectiva del último de ellos, no pudiendo ser hoy de otra manera, pues si ya el conocimiento de la cultura de los pueblos aislados es difícil de conocer, aún más el de un pueblo extinto.

\footnotetext{
9 Al respecto Zachary O’Hagan, doctorando de Lingüística de la Universidad de California, Berkeley, afirmó: “Jamás he escuchado una historia equivalente en ninguna otra parte; en cualquier círculo académico, eso se habría considerado un suceso poco ético”. (Ver: https:/ www.nytimes.com/es/2017/12/29/el-ultimo-hablante-de-una-lengua-ancestral-de-la-amazonia/)

10 Ver: https:/www.nytimes.com/es/2017/12/29/el-ultimo-hablante-de-una-lengua-ancestral-de-la-amazonia/

11 Aunando a su propia defensa, Alicea ha afirmado que "antes que nada era cristiana" y que si bien le "encanta la lengua", ama a la gente, sin embargo, más que a la lengua, y que "Con la bendición de Dios, esos niños tuvieron un futuro". (Ver: https:/www.nytimes.com/ es/2017/12/29/el-ultimo-hablante-de-una-lengua-ancestral-de-la-amazonia/).
} 


\section{Sobre el endónimo taushiro}

El nombre de taushiro que ha identificado a este pueblo no le es originario. Fueron los hombres blancos que en el pasado, aproximadamente a mediados del siglo XX, los llamaron de esta manera, cuando este pueblo empezó a tener contacto esporádico con los foráneos. Amadeo afirma al respecto: "Taushiro es lo que nos ha puesto los mestizo (sic). Atontu'tua son nuestro tribu, de nosotros. Eso es legítimo" (comunicación personal, 24 de febrero de 2016). Si el término taushiro significa algo con precisión, es difícil saberlo, y no hay rastro fidedigno que permita seguir su primigenio significado. En el Diccionario achuar-shiwiar/castellano se recoge el término "tawíshur", relacionado con la palabra taushiro, y hace referencia a que es un "grupo idiomático casi extinto que vive entre los ríos Corrientes y Tigre" (Fast, Warklentin y Fast, 1996, p. 270). Esta sola referencia le sirvió a O’Hagan para indicar que el término taushiro tiene claramente origen jíbaro (2015, p. 7). Sin embargo, pensamos que dicha conclusión es apresurada. Es sabido que los vecinos amazónicos de los taushiro, en el pasado, fueron los pueblos jíbaro: achuar, awajún y aguaruna. Es posible que estos grupos hayan escuchado a los mestizos mencionar a los taushiro llamándolos de este modo, y adecuaron dicha palabra a su propia fonología. De aquí que se haya transformado este término en tawíshur, lo cual explicaría por qué no tiene un significado en particular distinto al que hace referencia al grupo nativo.

Antes de taushiro a este pueblo se le denominó pinches o pinchis ${ }^{12}$. No obstante, estos términos no poseen familiaridad fonológica con otros términos originarios de la lengua taushiro. Estos exónimos son de larga data, pues son mencionados por los más antiguos registros y crónicas de jesuitas y exploradores de los siglos XVII y XVIII ${ }^{13}$. No obstante, Amadeo niega que pinche o pinchi haya identificado alguna vez a su gente: "Ese es otro tribu, ese es otro indígena. [...] es otra tribu, de repente su tribu [la de otras personas] será pinche, no sabemos" (comunicación personal, 24 de febrero de 2016). Esto respondió cuando se le preguntó si también reconocía esta identificación. La información clara con relación a que los taushiro y los pinche eran el mismo pueblo nos lo brinda Günter Tessmann (1999) en los años 30 y Avencio Villarejo (1943) en los años 40. Amadeo García nació en los 50, por lo tanto es muy probable que él no haya identificado nunca a su tribu con los llamados pinches.

Por los escritos de Alicea Ortiz (1976a) sabemos que los taushiro se autodenominaban ite'chi (gente, hombre), y Amadeo confirma esta referencia: "Ite'chi quiere decir 'nuestro tribu'" (comunicación personal, 18 de marzo de 2010). Alicea Ortiz nos dice que este término muestra el etnocentrismo de los taushiro, ya que con él se autorrefieren como la gente real o los auténticos hombres (1976a). Con ite'chi, pues, se distinguían de los demás hombres, valorándose los taushiro como superiores a aquéllos.

Tres términos, entonces, estuvieron relacionados como significantes de este pueblo: taushiro, ite'chi y pinche. Los dos primeros son aceptados por Amadeo García, el último no. Sin embargo, dado que el término ite'chi es menos recurrente, Amadeo gusta entonces de llamarse a sí mismo como taushiro. Mas no debemos olvidar que los últimos taushiro se dividían en dos grupos: los einontu'tua (los que comen pescado) y los atontu'tua (los que comen mitayo) (Alicea, 1976a, p.

12 Günter Tessmann afirmaba en 1930 que: “El nombre de 'Pinche’ procede de pinche = tucán. Versión española: Pinche” (1999, p. 320). Pero el lingüista norteamericano Zachary O’Hagan (2015) afirma que pinche es un exónimo de origen desconocido.

13 Por citar algunos, la crónica de 1684 del padre Thomas Santos señala al respecto: “Estos Asorunatoas nos dieron noticias del paraje donde asistían los Pinches y los Habitoas [...]" (Citado en de Figueroa, de Acuña y otros, 1986, p. 354); "Mi designio era el entrar primero a los Simigaies, para bajar por el Tigre a los Gualpayos y Pinches" (p. 345). Asimismo, la crónica de 1738 del jesuita Pablo Maroni señala: "[...] A esta se sigue día y medio largo de camino más abajo, a la otra reducción corta de Pinches, Pavas, Roamainas y Arazas, naciones un tiempo numerosas y que vivían entre el Pastasa y el Tigre” (1988, p. 97). El jesuita Franz Xavier Veigl, en 1768, señaló: “Más arriba del Pastaza está ubicada [...] la comarca de los Pinche y de algunas ramas de esta tribu como los Araza, los Pava, los Ushpa [...]" (2006, p. 113). 
1). La separación se debió a la decisión de un patrón con quien los taushiro trabajaban. Cabe la posibilidad de que la identificación de einon'tutua y atontu'tua se haya originado a partir de este hecho. Los einontu'tua fueron ubicados cerca de la comunidad de Bolognesi, por la quebrada Lejía (Alicea, 1976a), una quebrada de mediano caudal dado que es afluente directo del río Tigre, lo que les dio una mayor oportunidad de alimentarse con pescado que de alimentarse con carne de monte, pues los grandes animales de monte escaseaban en las zonas cercanas a los poblados. Los atontu'tua, por el contrario, permanecieron en las partes más profundas de la selva, por la quebrada de Aucayacu, afluente de la quebrada Aguaruna, afluente a su vez del río Tigre. Esta quebrada Aucayacu - que Amadeo incluso llama Aucayaquillo- es pequeña, de poco caudal, lo que no facilita la posibilidad de alimentarse con pescado. Por esta razón es que los atontu'tua preferían alimentarse con carne de monte (mitayo). Al permanecer en un territorio alejado de otros pueblos, tenían a su disposición una mayor cantidad de animales para cazar. Por ello, los primeros se denominaron einontu'tua (los que comen pescado) y los segundos atontu'tua (los que comen mitayo $)^{14}$.

Atontu’tua fue el endónimo del grupo taushiro al que pertenecía Amadeo García. Él afirma: "Atontu'tua son nuestro tribu, de nosotros. Eso es legítimo" (comunicación personal, 24 de febrero de 2016). En consecuencia, Amadeo es un taushiro pero sobre todo es un ite'chi atontu'tua. Esta es la denominación original de los taushiro de Amadeo, y la que este reconoce.

\section{Sobre la cosmovisión taushiro}

La cosmovisión es la forma cómo entendemos el mundo. En las culturas indígenas amazónicas, la cosmovisión -implicada íntimamente con las tradiciones mágico-religiosas-está implícitamente presente en el pensamiento de los hombres y subyace siempre a las acciones del colectivo social, pues tal y como sostuvo Lévi-Strauss: "No se puede vivir en un mundo no pensado" (Magaña, 1991, 281). Esto hace posible actuar en el mundo y modificarlo, por ello, "el hombre tiene por necesidad que poseer una cosmovisión, es decir, un mapa de ruta, una imagen de este mundo" (El Ojo Verde, 2004).

En estas sociedades tradicionales, el mundo no es solo el entorno ambiental, inmediato y único, sino también lo forman aquellos espacios más allá de las percepciones sensoriales, espacios de realidad que conllevan sus propias normas (Mayor y Bodmer, 2009, p. 83). Estos espacios son considerados como espacios de acción, pues son los lugares donde las cosas se dan, donde el sujeto vive: la comprensión de un espacio permite la comprensión del sujeto de dicho espacio y de los hechos que acaecen en él. Por ello, hace bien Vilcapoma al afirmar que: "La idea de espacio del hombre primitivo, aún cuando no haya estado sistematizada, se hallaba vinculada sincréticamente con el sujeto" (2010, p. 47).

Pablo Macera Dall'Orso y Carlos Dávila Herrera, en su introducción a El Ojo Verde (2004), son más puntuales en torno a la multiplicidad de los espacios en la cosmovisión amazónica. Nos dicen estos autores que la mayoría de los pueblos amazónicos reconocen únicamente tres lugares o espacios: el espacio del agua, el de la tierra y el de arriba (entendido este último sobre todo en términos de cielo, nubes o sol). Algunas distinciones, no obstante, aparecen. Por ejemplo, afirman los autores que algunos pueblos, como los nomatsiguenka que viven cerca de las estribaciones andinas, mencionan en su cosmovisión al espacio subterráneo de los cerros, diferenciándolos del de la tierra, lo cual es debido a que su geografía influye en su visión y comprensión del mundo. Del mismo modo, en la cosmovisión de los taushiro que nos lega Amadeo García no se hace mención al espacio de las aguas. Esta particularidad se debe, posiblemente, a que los taushiro,

14 Amadeo García ha confirmado estos significados. 
por su condición de aislados, no habitaron zonas cercanas a los grandes ríos, por lo que estos no formaron parte importante de su percepción sensible del mundo.

Todos los pueblos amazónicos tienen su cosmovisión. Lamentablemente, Amadeo García es hoy la única persona que nos puede informar sobre la cosmovisión taushiro, aunque no recuerda mayores detalles y solo nos puede brindar generalidades. Debido a este inconveniente, existe la posibilidad de que algunos datos que él nos brinda los haya incorporado tardíamente. Esto último, sin embargo, no nos suscita mayor problema, pues demostraría el dinamismo de la memoria de Amadeo como indígena amazónico respecto a los relatos de su pueblo, pues estos no regresarían hacia él, hacia su mente, de manera pasiva sino activa. Y si, por el contrario, lo que nos relató Amadeo fuera tal y como lo escuchó de su padre, entonces estaríamos ante una visión del mundo tal y como llegó inmediatamente antes de la desaparición total de los taushiro. En ambos casos, nuestra investigación es plausible. Creemos, no obstante, que lo primero tiene más sustento, pues los relatos son dinámicos en la oralidad, aún si no tuviesen ya el apoyo del pueblo del que formó parte.

Antes de abordar la cosmovisión taushiro, hemos de detenernos brevemente en su percepción del tiempo. No hay mayor información ni mitos que nos permitan extraer algunas interpretaciones. No obstante, y de acuerdo a Mircea Eliade (1951), podemos afirmar que los taushiro tuvieron una concepción cíclica del tiempo, no distinta a la de otros pueblos amazónicos. En cierta forma, solo un dato puede corroborar nuestra hipótesis, y tiene que ver con cómo los taushiro medían o calculaban el tiempo cuando de temporadas largas se trataba, esto siempre según Amadeo, pues al respecto Alicea Ortiz no ofrece ninguna referencia: "Del año también, decían [los abuelos], porque cada año echen cualquier planta que se ve aquí, cada año se echa huayo, cada año se echa huayo (oan'cu). Así nomás se ponía del año" (comunicación personal, 19 de marzo de 2010). Aquí lo que nos quiere decir Amadeo es que el año en los taushiro era calculado cuando alguna planta echaba su huayo (su fruto). Este cálculo estaba, pues, asociado a este ciclo natural de los brotes y rebrotes del huayo, por lo que los "años" no eran ni tenían por qué ser precisos.

Los taushiro, pues, miraban la naturaleza para conocer la duración de un tiempo, y organizaban sus faenas en virtud de estos fenómenos. Posiblemente hayan tenido muchas formas de medir el tiempo ya que, en general, y como apunta Vilcapoma, las sociedades tradicionales consideran que el tiempo "está asociado a los niveles cósmicos, sean estos como movimientos de estrellas o astros, como también está asociado al ciclo de la vida: nacimiento, matrimonio y muerte, que también es otra forma de ver trascurrir el tiempo" (Vilcapoma, 2010, p. 48).

Habiendo hecho esta atingencia, abordemos ahora lo que respecta a la cosmovisión taushiro, el cómo veían el mundo (su mundo), siempre según Amadeo García. Tres zonas o espacios, cuyos nombres en lengua taushiro Amadeo no recuerda, formaban su mundo vital. A estos espacios, a falta de los nombres originarios, los denominaremos espacio de abajo, espacio de la gente y espacio de arriba.

\section{Espacio de abajo}

Sobre el espacio de abajo Amadeo narra lo que contaban los abuelos y, como veremos, no se limita a describir este espacio, sino que nos recordará una breve leyenda sobre cómo es que supieron los antiguos taushiro de la existencia de ese mundo. Además, se refiere a cómo es que el "brujo taushiro" pudo acceder a este mundo tomando ayahuasca (Banisteriopsis caapi), adjudicando a esta bebida un poder trascendente, lo cual es común y propio de los pueblos amazónicos. Nos dice Amadeo: 
En cierta ocasión un abuelo (antepasado) suyo estaba cavando un hueco profundo (u'untu u'cue') que sirviera como trampa para los animales, cuando de pronto fue empujado por la madre del espacio de abajo (comunicación personal, 20 de marzo de 2010$)^{15}$.

En otro momento Amadeo afirma que no fue empujado por nadie, que de pronto la tierra se abrió, pues se había "roto la profundidad" (comunicación personal, 20 de marzo de 2010). Al caer, el abuelo desapareció. Un brujo (yachova i'techi), luego de tomar su ayahuasca (anu'vu') o su toé, "vio" al desaparecido "debajo" de la tierra ${ }^{16}$. Este luego salió con ayuda del brujo (Amadeo especifica que apareció tras un mes aproximadamente, aunque parece ser que esto lo dice solo como una referencia) y narró que debajo de la tierra (u'untu) hay otro mundo: con personas (ava'vu), casas (ahan), árboles (avah), ríos (vei) y sus peces (ei'na) ("no habiendo peces ¿qué cosa comerá la gente?”, reflexiona Amadeo), y frutas como caimito (canani), piña (vanta), guaba, entre otras (comunicación personal, 20 de marzo de 2010) ${ }^{17}$.

Al parecer, aunque esto no lo deja muy claro, los taushiro pensaban que esas personas eran los espíritus de las carachupas ${ }^{18}$. Sin embargo, y esto sí lo dice con claridad, esas personas eran buenas si bien no eran taushiro, aunque sus casas eran parecidas a las de estos, construidas con hojas de irapay (comunicación personal, 20 de marzo de 2010). Según Amadeo, este abuelo logró salir del mundo de abajo y narró lo que vio, aunque también afirma nuestro informante que él tiene "un abuelo perdido acá adentro de la tierra" (comunicación personal, 20 de marzo de 2010); es decir, da a entender que continúa perdido. No es nuestra intención dilucidar este contrapase, pues se sabe que es bastante común en los relatos orales encontrar algunas contradicciones e incoherencias. Estas salen a relucir toda vez que el relato vuelve a emanar en la oralidad dándonos a entender que lo importante, finalmente, no es la coherencia ni la consistencia de lo que se narra (finalmente los mitos no deben ser tomados como hechos históricos) sino la temática misma, o la "armadura" como diría Lévi-Strauss (1997), pues esta nos permite conocer y comprender la cultura ${ }^{19}$. En este sentido, este pequeño relato sobre la existencia de un subespacio no está exento de contradicción y, sin embargo, no afecta el meollo de la cosmovisión.

\section{Espacio de la gente (de los ite'chi)}

Este es el plano de la vida terrestre, donde hay árboles (avah), ríos (vei), quebradas (vei anta'ca), animales para comer, donde se construyen las viviendas (ahan), donde nacen los hijos (nacho), donde se caza, donde se socializa y donde se libran las peleas. Aquí están los ite'chi (gente), tanto del grupo de los atontu'tua como de los einontu'tua. En este espacio se encuentran, asimismo, los espíritus buenos (a'ta'ca'tua) y las madres de los seres del monte, de animales y de árboles. Este es el espacio que perciben los taushiro, en el que viven y en el que interactúan. Es el espacio al que pertenecen, del cual se sirven y en el cual trasforman.

\footnotetext{
15 Los taushiro solían cavar profundos huecos y clavar estacas en su interior. Luego cubrían el agujero con ramas y hojas, y esperaban a que un distraído animal caiga en él y muera atravesado. Muchos pobladores recuerdan el miedo que tenían de acercarse a la zona de los taushiro justamente porque en sus alrededores existían muchos de estos agujeros.

16 La ayahuasca y el toé (floripondio, Brugmansia arborea) son plantas psicoactivas que al ser ingeridas, según las tradiciones locales, producen ciertos efectos mágicos: viajar a otros espacios, ver el futuro, entre otros.

$17 A v a^{\prime} v u$ hace referencia a las hombres en general, mientras que ite'chi a los propios taushiro. Por eso, en este espacio de abajo no habían taushiros (ite'chi) sino otras personas (ava'vu).

18 Armadillos.

19 Tal y como nos lo recuerda Néstor Taipe Campos (2004, p. 20), Lévi-Strauss llama armadura al núcleo duro de un conjunto de versiones de un mito, que es lo que mantiene el mensaje principal al margen de los detalles de una u otras versiones del mismo mito.
} 


\section{Espacio de arriba}

Los taushiro también creían en el espacio de arriba. No obstante, la descripción que nos facilita Amadeo es algo peculiar. En este lugar habían casas (ahan) parecidas a las de los taushiros, confeccionadas con hojas de irapay. Los hombres, que eran gente buena, "eran parecidos como nosotros mismos" y algunos tomaban ayahuasca (anu'vu'). También habían animales como "tigres" (otorongos o jaguares) (he'i), sachavacas ( $\left.x e^{\prime} h i\right)$ y serpientes (víboras o culebras, $h u^{\prime} n o$ ') (comunicación personal, 20 y 24 de marzo de 2010 y 19 de febrero de 2016).

Más arriba de donde se halla esa gente está el Sol ('akku), y más arriba la Luna (a’tova), y más arriba aún las estrellas ('a'chivi) ${ }^{20}$. Que el Sol esté más abajo de la Luna parece ser explicado por el hecho de que es el sol el que alumbra más y quema más en la tierra mientras la luna alumbra menos y no quema (comunicación personal, 20 y 22 de marzo de 2010). El símil, en su experiencia nocturna que explica este particular, es claro: el fuego de la fogata cercana (el Sol) alumbra y quema más que el de la fogata lejana (la Luna), que ni siquiera alumbra pero cuya luz se ve. En este espacio de arriba, en consecuencia, hace más calor porque está más cerca del sol (comunicación personal, 20 de marzo de 2010). Así se lo contaba su papá, afirma Amadeo, con quien marca cierta distancia con lo que conoce hoy:

Allá, dicen, es como aquí nomás en la tierra, así contaban los abuelos, sí sí sí. Por eso dicen es el Sol, allá dice es más candela [caliente] que, más que lo que está aquí abajo [en la tierra], ellos decían así, pue, más candela que aquí, pue hermano [porque] está más cerca del Sol ya. Y así contaban pues hermano (comunicación personal, 20 de marzo de 2010).

La Luna y las estrellas no están juntas, pues “cada uno[a] está en su planeta” (comunicación personal, 22 de marzo de 2010) ${ }^{21}$. Sin embargo, Amadeo no asegura si la luna está sola allá en el cielo ( $a^{\prime}$ can $)$ cuando aparece en las noches ( $i^{\prime}$ chia), pues las estrellas no la acompañarían porque estarían lejos de ella. Las nubes (a’can) están más abajo que el sol (comunicación personal, 20 de marzo de 2010) $)^{22}$.

Desconoce Amadeo si sus ancestros creían si "allá arriba" había río. Sin embargo, hay árboles con frutos, árboles pequeños, bajitos, "como chala" (comunicación personal, 20 de marzo de 2010). ¿Cómo es que Amadeo tiene la idea de que arriba hay árboles pequeños como chala? ¿Será que tenga alguna referencia de la sierra peruana, que es altura, y que allá, efectivamente, existen arbustos pequeños como chala? Amadeo nunca ha ido a la sierra pero cabe la posibilidad de que en algún momento se lo hayan hecho saber y, de repente, descrito los arbustos allá existentes. ¿Puede estar sintetizando estos supuestos conocimientos sobre la sierra con el mundo de arriba?

La gente que estaba arriba - continúa relatándonos Amadeo- se mantenía colgada cabeza abajo, pero no caía, aunque podía caer, que esto contaban "mis abuelos [los brujos], no yo" (comunicación personal, 22 de marzo de 2010) ${ }^{23}$. Nuevamente, Amadeo marca distancia respecto

20 Lo que ha aprendido hoy Amadeo le ha permitido tener una actitud escéptica respecto de lo que creían sus antepasados. Por este motivo, no sabe decir con certeza si el Sol o la Luna están más arriba el uno del otro, aunque cree que es el Sol: "El Sol está más arriba que la Luna quizás" (comunicación personal, 20 de marzo de 2010).

21 Cuando Amadeo dice "planeta" parece querer decir que cada cual (la Luna y las estrellas) está en su lugar, alejada la una de las otras. Aquí Amadeo parece que está mezclando lo que conoce hoy con el relato sobre lo que creían sus ancestros.

22 En el Vocabulario taushiro de Alicea Ortiz (1975b) se registra que tanto nube como cielo se dice en lengua taushiro a'can. Esto lo corrobora Amadeo García.

23 En otro momento, Amadeo narró que sus abuelos decían que sí podían caer (o que habían caído en algún momento), pues así como de la tierra uno puede caer hacia más abajo (en un agujero), así esa gente que estaba "allá arriba” también podían caer (comunicación personal, 20 de marzo de 2010). 
de las creencias de sus antepasados, pues solo ellos podían "subir" (o un abuelo "subió" una sola vez) ya que tomaban su toé (comunicación personal, 20 de marzo de 2010) ${ }^{24}$.

Aparte de los "brujos" (yachova i’techi), ningún taushiro ha visto jamás a esa gente "de arriba" porque estas personas se encontraban más allá de la visión que del cielo se puede tener (comunicación personal, 22 de marzo de 2010) ${ }^{25}$. Esa gente, contaban los brujos, golpeaba con fuerza el cielo ( $a^{\prime}$ can) con unas aletas (de árboles) y por eso es que el cielo tronaba (comunicación personal, 20 de marzo de 2010). También, y con seguridad por influjo de las creencias occidentales, nos dice nuestro informante que los taushiro pensaban que eran las almas de los hombres que al morir iban al cielo, y eran ellas las que golpeaban con las aletas el cielo: "Taushiro pensaban que eso que truena, ahí la gente dicen allá, los que están arriba, le golpean aleta arriba, así contaban los brujos. Quiere decir un aleta de un árbol, [...] un aleta así ancho, madera. Le golpean para que suene, así igualito truena, [...] los muertos golpean esa aleta han dicho [los abuelos]" (comunicación personal, 20 de marzo de 2010). Esta es la explicación mítica de los taushiro sobre por qué el cielo tronaba en ciertas ocasiones. Sin embargo, al afirmar Amadeo que eran las almas de los muertos las que hacían tronar el cielo, no podemos dejar de pensar en las creencias cristianas que ha aprendido en relación a que las almas de los muertos van al cielo, sobre todo porque los taushiro pensaban que las almas de los fallecidos se quedaban en la misma selva junto con los vivos (comunicación personal, 22 de marzo de 2010). Parece claro, pues, sobre este particular, que Amadeo García ha creado un sincretismo entre las creencias de la cultura a la que perteneció y las creencias occidentales que luego adoptó.

Tomando en cuenta sus actuales conocimientos sobre el mundo, y los de sus ancestros, Amadeo nos dice que todo eso existía antes, cuando los taushiro vivían y creían en todo ello, aunque ahora ya no hay animales ni gente "allá arriba". Afirma esto último, ya que es lo que conoce hoy (comunicación personal, 20 de marzo de 2010).

Esta es la visión que, según nos dice Amadeo, tenían los taushiro sobre el espacio de abajo, el de la gente y el de arriba. Sin embargo, la descripción que nos ha facilitado en distintas conversaciones ha dejado claro que no recuerda con exactitud ciertos pormenores acerca de lo que creían sus abuelos sobre este asunto, pues en algunos detalles se hallan imprecisiones. Creemos que estas imprecisiones, no conscientes, se deben al intento de mostrar las creencias de su pueblo de una manera más completa o plausible, no siendo esta actitud un yerro en absoluto, pues si muchos de los detalles no son tal y como lo creyeron los taushiros hasta los tiempos de Amadeo, vale el intento de nuestro informante de reivindicar a su pueblo en sus creencias, las cuales fueron suyas en algún momento de su niñez.

\section{Sobre la cosmogonía taushiro}

Amadeo aprendió la idea de la creación del mundo (por Dios) en el ILV. Él fue, nos dice, quien llevó esa "nueva noticia" a su familia, pues los taushiro nunca pensaron de este modo ${ }^{26}$. Para los taushiro, el mundo siempre habría estado ahí (comunicación personal, 20 de marzo de 2010). Si efectivamente esto es así, entonces se puede entender por qué Amadeo dice no recordar nada sobre lo que en este asunto pudiera haber escuchado de su padre, y a su vez éste de los viejos taushiro. Igualmente, no recuerda haber escuchado nada sobre el fin del mundo, aunque lo relaciona con el hecho de que la Luna se torne oscura y oscurezca todo el mundo, como habría acontecido hace mucho tiempo, según una vieja leyenda (comunicación personal, 20 de marzo de 2010).

24 Amadeo ha reiterado en no pocas ocasiones que tuvo abuelos (antepasados lejanos) que fueron "brujos".

25 Amadeo explica que el "brujo" y el curandero (el médico) son lo mismo: “[...] brujo quiere decir médico. [...] son dos cosas (la misma cosa quiere decir). Dicen médico y dicen brujo también” (comunicación personal, 19 de marzo de 2010).

$26 \mathrm{El}$ concepto de Dios no formaba parte de la mentalidad taushiro, ni siquiera el de dioses, solo el de espíritus del monte. 
Los taushiro, asevera nuestro informante, pensaban que este es el único mundo (en sus tres niveles espaciales) y que por ello resultaba imposible que hubiera un mundo distinto. Por eso creían que los espíritus, incluso los de sus antepasados, poblaban el bosque. Esta es la conclusión a la que llega Amadeo García a partir del hecho que nunca oyó de sus padres el que sus antepasados hablaran sobre este asunto (comunicación personal, 20 de marzo de 2010). Es decir, no es que sus antepasados hayan negado la existencia de otro mundo, simplemente, al parecer, nunca lo pensaron; esta idea entonces no formaba parte de sus creencias ni siquiera para ser negada. Lo mismo podría concluirse respecto del origen del mundo, aunque esto último resulta difícil de sostener con certeza.

Respecto de los cuerpos celestes, como la Luna, el Sol y las estrellas, los relatos que rememora Amadeo son también bastante escasos. Afirma que sus padres nunca le dijeron, por ejemplo, que la Luna y el Sol fueron gente en el pasado muy lejano. No recuerda relato alguno parecido, a diferencia de otros pueblos de la Amazonía que contienen relatos al respecto en su ideario mitológico. Los quichua, por ejemplo, cuentan que el sol, cuando era niño y estaba aún en la tierra, había comido mucho ají y que por eso quemaba mucho, y que su hermana era la Luna (El Ojo Verde, 2004). Amadeo mostró cierta sorpresa cuando se le hizo saber este relato quichua. Él, por el contrario, nos dice que los taushiro pensaban que la Luna y el Sol siempre habían estado ahí, aunque antes no hayan alumbrado mucho (comunicación personal, 22 de marzo de 2010).

Amadeo recuerda que le contaron alguna vez acerca de los brujos einontu'tua, quienes tras tomar ayahuasca (anu'vu'), vieron en cierta ocasión a la "madre" del Sol, y también a la de la Luna. Acotó luego: "Han visto su madre del sol”, pues "hay madre", dijo (comunicación personal, 22 de marzo de 2010). Esto, aclara Amadeo, contaban los abuelos de los einontu'tua, no los suyos, es decir, durante los tiempos en que ni siquiera su papá vivía, hace mucho tiempo, "en los tiempos en que no había nadie" (comunicación personal, 22 de marzo de 2010).

Algunos pueblos creen que el mundo flota sobre el agua o que está sostenido por una serpiente. Nada parecido, afirma Amadeo, ha escuchado de sus padres (comunicación personal, 22 de marzo de 2010). Pero sí recuerda, no obstante, que decían que la Luna daba vueltas, que "por aquí entra (señalando el occidente) y por aquí sale (señalando el oriente), igual que el Sol" (comunicación personal, 22 de marzo de 2010), mientras que las estrellas no se movían. Esto último inmediatamente hace recordar a los viejos observadores del cielo que llamaron "estrellas fijas" a ese cúmulo de puntos centellantes que efectivamente parecían no moverse, mientras que otros cuerpos celestes, más grandes por cierto, sí lo hacen, en este caso la Luna y el Sol. Y estos no solo se movían sino que, sobre todo, daban vueltas, ¿a qué?: a la Tierra. La Tierra, sin embargo, no era pensada por los taushiro como redonda, pues Amadeo señala que sus padres le decían que si se camina de frente no se hallaba el fin (comunicación personal, 20 de marzo de 2010). Esta mención, insta a suponer que tenían la idea vaga de que la Tierra tenía una superficie plana, idea común a todo pensamiento tradicional, muy antiguo, y más consecuente con lo que se observa directamente, como todos los hombres de pensamiento práctico que describen de acuerdo a lo que observan, sin prestar mayor atención a algún problema que pudiera surgir a partir de sus descripciones. Los taushiro, según Amadeo, pensaban que la Luna y el Sol salen y entran, dando vueltas a una Tierra que es infinita a la distancia. ¿Salen y emergen de la tierra entonces?

Antiguos habitantes de otras latitudes pensaban que el Sol, por ejemplo, emergía del mar y/o se hundía luego en el mar tras el día, por ello no resulta extraño deducir que los taushiro hayan pensado algo parecido, pero sin el mar, pues este no formaba parte de su cosmovisión. 
Entonces, ¿emergían (o nacían) de la tierra e igualmente se hundían (o morían) luego en ella, para a continuación emerger (nacer) nuevamente? ¿Esa muerte y ese nacer de la Luna y el Sol son esas "vueltas" de las que habla Amadeo, según recuerda de los taushiro? ${ }^{27}$ Esta es, obviamente, una pregunta lógica a la que llegamos nosotros y no le exigimos a los taushiro respuesta alguna, pero es un importante indicador que nos permite, entre otras cosas, darnos cuenta del estado de practicidad al que llegó este pueblo indígena al momento de enfrentar el mundo, en este caso al observarlo y tratar de conocerlo, y todo esto al margen de la coherencia que siempre busca el pensamiento occidental, aquí representado por nosotros.

La figura entonces resulta del siguiente modo: "Si me haces una pregunta, te la respondo. Si me haces otra pregunta, también te la respondo. Si a partir de mis respuestas dedujiste un problema, ese problema no es mío sino tuyo, pues fuiste tú quien lo halló. Yo respondí bien”. Este podría ser, ciertamente, el razonamiento que fundamentaría la actitud práctica del pueblo taushiro al querer responder por el mundo, o la del propio Amadeo, en el caso que él haya mezclado algunas ideas suyas al momento de querer decirnos lo que creían sus ancestros.

\section{Conclusión}

Amadeo nos ha relatado lo que pensaban sus padres y sus abuelos sobre el mundo, pero somos conscientes de que no podemos concluir, obviamente, a partir de estos escasos datos, que los taushiro pensaban que la Tierra era el centro de algo más grande en el que la Luna y el Sol se mostraban en un tránsito regular, como tampoco podemos afirmar que pensaban que la Tierra permanecía inmóvil, como las estrellas, siendo el Sol y la Luna las móviles. Pero lo que sí podemos decir, con toda seguridad, es que sus observaciones del cielo, y lo que dejaron dicho de él, nos devuelve a ese estadio primitivo de la humanidad, y así como en la antigüedad los hombres crearon inconscientemente historias que explicaban el porqué de los cielos, por qué son como son, igualmente pensamos que hubo historias taushiro al respecto, mitos que hoy lamentablemente están perdidos.

Dudamos que Amadeo haya escuchado esas historias de su padre, y si lo hizo no le prestó al parecer mayor atención, y por eso nos asegura no recordar nada al respecto. Tomemos en cuenta que su pueblo estaba ya casi extinto, y debido a su escasa población, la misma que se redujo solo a su familia íntima, dejaron de danzar y cantar sus canciones, y de tocar y fabricar sus instrumentos musicales $^{28}$. Y si bien se mantuvieron en aislamiento, habían ya adoptado muchas costumbres y elementos foráneos a raíz de los contactos esporádicos que habían tenido con gente mestiza. Y así como dejaron mucho de sus ancestrales tradiciones, muchos de sus relatos fueron olvidados. Y si tomamos en cuenta la tesis de algunos estudiosos como Malinowski (1974), Eliade (1994) y Ferdinandy (1961), según la cual los mitos dan fundamento al rito, y al hacerlo aquéllos se hacen presente en estos, se actualizan, se vivifican. Y recordando que los últimos taushiro, según nos dice Amadeo, ya no practicaban ritos, pues eran muy pocos, entonces el mito dejó de hacerse presente, dejó de actualizarse, de vivificarse ${ }^{29}$. No obstante, algunos fueron evocados por su padre, pero de estos muy pocos recuerda Amadeo. Los que todavía recuerda son los que aquí hemos recogido en relación a su cosmovisión y cosmogonía.

\footnotetext{
27 Esta información sobre que el Sol y la Luna surgen (o nacen) y emergen (o mueren) todos los días y noches, respectivamente, nos hace recordar la antigua visión que sobre el astro Sol tenía el filósofo griego del siglo V a.C. Heráclito de Éfeso: "El sol es nuevo cada día" (Aristóteles. Metereologica, II, 355a, 14)

28 Estos instrumentos eran básicamente flautas elaboradas a partir de huesos o cañas, y tambores rudimentarios.

29 Al menos él no participó de ninguno, ni nunca vio alguno.
} 


\section{Bibliografía}

Alicea, Neftalí (1975a). Análisis preliminar de la gramática del idioma taushiro. Lima: Instituto Lingüístico de Verano, Ministerio de Educación.

Alicea, Neftalí (1975b). Vocabulario taushiro. Lima: Instituto Lingüístico de Verano, Ministerio de Educación.

Alicea, Neftalí (1975c). Análisis fonético preliminar del idioma taushiro. Lima: Instituto Lingüístico de Verano, Ministerio de Educación.

Alicea, Neftalí (1975d). Ejercicios y problemas de cálculo en taushiro y castellano. Lima: Instituto Lingüístico de Verano, Ministerio de Educación.

Alicea, Neftalí (1975e). Un texto taushiro. Lima: Instituto Lingüístico de Verano, Ministerio de Educación.

Alicea, Neftalí (1976a). Apuntes sobre la cultura taushiro. Lima: Instituto Lingüístico de Verano, Ministerio de Educación.

Alicea, Neftalí (1976b). Taushiro, materiales para estudios fonológicos I. Lima: Instituto Lingüístico de Verano, Ministerio de Educación.

Chávez, Margarethe (1976). Instrumentos musicales tradicionales de varios grupos de la selva peruana. Lima: Instituto Lingüístico de Verano, Ministerio de Educación.

Álvarez, José (s/f). Amadeo, el último de los taushiro. Recuperado el 25 de enero de 2016 de https://www.servindi. org/actualidad/5004

de Figueroa, Francisco, Cristóbal de Acuña y otros (1986). Informe de jesuitas en el Amazonas, 1660-1684. Iquitos: Instituto de Investigaciones de la Amazonía Peruana, Centro de Estudios Teológicos de la Amazonía.

Echered, Stephen (1975). Comentario sobre el análisis fonémico preliminar del idioma Taushiro. Lima. Instituto Lingüístico de Verano, Ministerio de Educación.

El Ojo Verde (2004). Lima: Fundación Telefónica, Aidesep, Formabiap.

Eliade, Mircea (1951). El mito del eterno retorno. Madrid: Emecé.

Eliade, Mircea (1994). Mito y realidad. Bogotá: Labor.

Fast, Gerhard, Rubi Warkentin y Daniel Fast (1996). Diccionario achuar-shiwiar/castellano. Lima: Instituto Lingüístico de Verano, Ministerio de Educación.

Ferdinandy, Miguel de (1961). En torno al pensar mítico. Berlín: Colloquiuer Verlag.

Lévi-Strauss, Claude. (1997). Mitológicas IV: El hombre desnudo. México: Siglo Veintiuno Editores.

Magaña, Edmundo (1991). “Entrevista a Claude Levi-Strauss”. Anthropologica, 9 (9): 277-285.

Malinowski, Bronislaw (1974). Magia, ciencia y religión. Barcelona: Ariel.

Maroni, Pablo (1988). Noticias auténticas del famoso río Marañón, 1738 (1638-1738). Iquitos: Instituto de Investigaciones de la Amazonía Peruana, Centro de Estudios Teológicos de la Amazonía.

Mayor, Pedro y Richard Bodmer (2009). Pueblos indígenas de la Amazonia peruana. Iquitos: Centro de Estudios Teológicos de la Amazonía.

O’Hagan, Zachary (2015). Taushiro and the status of language isolates in Northwest Amazonia. Recuperado el 12 de noviembre de 2017 de http://linguistics.berkeley.edu/ zjohagan/pdflinks/ohagan_fforum_taushiro_ isolates_vl.pdf

Pérez, Juanita (2008). Análisis morfológico-semántico de los verbos de desplazamiento en taushiro (tesis de licenciatura). Lima: Universidad Nacional Mayor de San Marcos.

Ribeiro, Darcy y Marie Ruth Wise (1978). Los grupos étnicos de la Amazonia peruana. Lima: Instituto Lingüístico de Verano, Ministerio de Educación.

Taipe, Néstor (2004). Los mitos. Consensos, aproximaciones y distanciamientos teóricos. Gazeta de antropología, 20. Recuperado el 1 de octubre de 2018 de http://www.ugr.es/ pwlac/G20_16NestorGodofredo_Taipe_ Campos.html

Tessmann, Günther (1999). Los indígenas del Perú nororiental. Quito: Abya-Yala. 
Veigl, Francisco Xavier (2006). Noticias detalladas sobre el estado de la Provincia de Maynas en América meridional hasta el año de 1768. Iquitos: Centro de Estudios Teológicos de la Amazonía.

Vilcapoma, José Carlos (2010). De bestiarios a la mitología andina. Insectos en la metáfora cultural. Lima: Asamblea Nacional de Rectores.

Villarejo, Avencio (1943). Así es la selva. Lima: Compañía de Impresiones y Publicidad.

Presentado: 22 abril 2019

Aceptado: 21 octubre 2019

Publicado online: 15 julio 2020 
